\title{
Personality and suicidal ideation in the elderly: factorial invariance and latent means structures across age
}

\section{Paolo Iliceto, Emanuele Fino, Ugo Sabatello \& Gabriella Candilera}

To cite this article: Paolo Iliceto, Emanuele Fino, Ugo Sabatello \& Gabriella Candilera (2014) Personality and suicidal ideation in the elderly: factorial invariance and latent means structures across age, Aging \& Mental Health, 18:6, 792-800, DOI: 10.1080/13607863.2014.880404

To link to this article: https://doi.org/10.1080/13607863.2014.880404

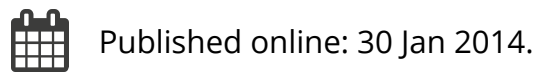

Submit your article to this journal ¿

Lll Article views: 412

Q View related articles ¿

View Crossmark data ${ }^{\top}$

Citing articles: 8 View citing articles $\square$ 


\title{
Personality and suicidal ideation in the elderly: factorial invariance and latent means structures across age
}

\author{
Paolo Iliceto $^{\mathrm{a}}$, Emanuele Fino $^{\mathrm{b} *}$, Ugo Sabatello $^{\mathrm{c}}$ and Gabriella Candilera ${ }^{\mathrm{d}}$ \\ ${ }^{a}$ S\&P Statistics and Psychometrics Ltd, Rome, Italy; ${ }^{b}$ Department of Developmental and Social Psychology, Sapienza University of \\ Rome, Rome, Italy; ${ }^{c}$ Department of Pediatrics and Child Neuropsychiatry, Sapienza University of Rome, Italy; ${ }^{d}$ Clinical Psychologist, \\ Private Practice, Rome, Italy
}

(Received 13 September 2013; accepted 30 December 2013)

\begin{abstract}
Objectives: Suicide among the elderly is a dramatic global health problem. Although fatal attempts are frequent in the elderly, research indicated that they rarely present long-term elaboration of suicidal ideation and communicate their intents. Consequently, risk factor detection and assessment are salient. Although evidence on the association between personality and suicidal ideation in young adults is accumulating, little is known about its relevance in the elderly. The purpose of the present study was to analyze the components of a measurement model that are invariant across young adults and older adults and then investigate the relations among dimensions of personality and suicide risk. We postulated a specific relation pattern a priori and tested the hypotheses statistically in order to examine the models for equivalency of the factorial measurement.

Method: We investigated 316 young adults and 339 older adults, who were administered self-report questionnaires to assess depression, hopelessness, alternative five-factor model of personality, and self-other perception.

Results: Multigroup confirmatory factor analyses were conducted, yielding a final model with excellent fit to the data. This model showed a similar pattern of associations between suicidal ideation and personality across both groups.

Conclusions: Although the elderly are exposed to specific life stressors associated with suicidal ideation, our findings suggest that the elderly and young adults may be similar on personality and psychopathology variables predicting suicidal ideation than previously hypothesized. Implications are provided for enhanced assessment and intervention of the elderly high in neuroticism, depression, hopelessness, and with negative self-other perception.
\end{abstract}

Keywords: elderly; neuroticism; extraversion; suicide; hopelessness

\section{Introduction}

Suicide among the elderly is a dramatic global health problem (World Health Organization, 2012). In industrialized countries, suicides in the elderly are more frequent than in other age groups, and in the last decade such trend has seen a substantial increase (Baker, Hu, Wilcox, \& Baker, 2013; Ciulla et al., 2014; Legleye, Beck, PerettiWatel, Chau, \& Firdion, 2010). In Italy, suicide is the third major cause of death in the adult population, and rates tend to rise with age (Pompili et al., 2010). Recent epidemiological studies indicate a death rate of 6.1/ 100,000 inhabitants among individuals aged 25-44, 8.4 among those aged 45-64, and 11.3 among those aged $>65$ (Istituto Nazionale di Statistica, 2011).

Although fatal attempts in the elderly are more frequent than in younger adults, there is evidence that the elderly are less likely to present long-term elaboration of suicidal thoughts and to communicate their intent and ideation (Conwell et al., 1998). Consequently, risk detection and timely intervention are particularly salient. However, the progressive increase in average life expectancy and the aging of the population exhort researchers to investigate and assess risk factors for suicidal ideation (SI) in the elderly.

Depression and hopelessness have been most consistently indicated as major predictors of SI in the elderly
(Pompili et al., 2008; Szanto, Prigerson, \& Reynolds III, 2001) as well as in younger adults (Haaga et al., 2002; Vrshek-Schallhorn, Czarlinski, Mineka, Zinbarg, \& Craske, 2011). However, different life stressors mark the emergence of such conditions in the two groups, i.e. mainly retirement, social isolation, and loss of a partner in the elderly (Juurlink, Herrmann, Szalai, Kopp, \& Redelmeier, 2004), and negative childhood experiences, poverty, ill-treatment in youth, and drug abuse (Pompili et al., 2011) in young adults. In particular, hopelessness has been reported as the most common emotion experienced among suicidal individuals (Shneidman, 1996), and research supports a positive relation between scores at the Beck Hopelessness Scale (BHS) (Beck, Weissman, Lester, \& Trexler, 1974) and measures of depression, suicidal intent, and ideation in clinical and nonclinical populations.

Furthermore, to date, few studies have investigated suicidality in the elderly in relation to specific personality traits. Lynch et al. (1999) found in a sample of suicidal old adults that chronic behavioral and personality problems were related to previous episodes and early onset of depression. Useda, Duberstein, Conner, and Conwell (2004) found associations between depression, hopelessness, and SI in the elderly within the broader framework of neuroticism and introversion, and Tsoh et al. (2005)

*Corresponding author. Email: emanuele.fino@uniroma1.it 
reported a positive association between depression and neuroticism, and a negative association between depression and extraversion in old adults with previous suicide attempt. In the same vein, Wiktorsson et al. (2013) found that suicide attempters aged 75 and above scored higher on neuroticism than comparisons, and lower on the extraversion scale.

Research has recently addressed individual differences in SI to internal working models (Davaji, Valizadeh, \& Nikamal, 2010; Sheftall, Mathias, Furr, \& Dougherty, 2013). According to Bowlby's $(1969,1973,1980)$ theory of personality development, early life experiences of attachment impact later self-other perceptions, determining significant variations in relationships functioning across life stages. Consistently, previous studies showed that adults with less secure attachment styles are characterized by less self-confidence and higher levels of negative effect, and are more likely to ideate and attempt suicide (Fraley \& Shaver, 2000).

In addition, although evidence on the role of personality dimensions in suicide in young adults is accumulating, little is known about their relevance in the elderly. However, to date most of the research on SI has employed the NEO Personality Inventory (NEO-PI; Costa \& McCrae, 1992). The NEO-PI represents a lexical approach to the assessment of personality. More recently, theorists have focused on the association between personality traits and relevant behavioral and biological characteristics (Block, 1995; Zuckerman, 1992), going beyond the descriptive analysis of personality, toward a causal and psychobiological approach. In particular, Zuckerman elaborated an alternative five-factor model of personality, in which traits present psychophysiological correlates and reliability across cultures (Zuckerman, Kuhlman, Joireman, Teta, \& Kraft, 1993). Understanding the interplay between such personality characteristics and psychopathology will aid clinicians in the identification and assessment of the elderly who are at risk of suicide.

Consequently, the purpose of the present study was to analyze the components of a measurement model that are invariant across the young adults and the elderly, and then investigate the relations among dimensions of personality and SI risk. We postulated a specific relationship pattern a priori and then tested the hypotheses statistically in order to examine the models for equivalency of the factorial measurement. Specifically, nine scales representing depression, hopelessness, attachment representations of the self and the other, and the alternative five-factor model of personality, as well as the underlying latent structure of these observed variables characterizing dimensions of personality and SI risk, were tested in young adults and older adults.

\section{Method}

\section{Participants}

From November 2012 to May 2013, 655 participants aged 18-75 years were contacted at universities, markets, supermarkets, shops, banks, public parks, post offices, and senior centers in three Italian regions: Lombardia, Veneto, and Lazio, and their respective districts. These three nonrandomly selected regions are highly representative of the current demographic background of Italy. Lombardia and Veneto are located in the north part of the country, with approximately 9 million and 5 million residents, respectively, while Lazio is located in the central part of the country, with more than 5.5 million residents. All participants came from lower to upper middle class, with various educational and socioeconomic backgrounds, representing well enough the Italian population. The respondents voluntarily participated in this study after providing written informed consent. We created two 17-year age groups on the basis of participants' age: the Young Adults and the Older Adults. The Young Adults $(N=339)$ group ranged from 18 to 35 years (mean $=26.2$; $\mathrm{SD}=3.8$ ) and the Older Adults group $(N=316)$ ranged from 58 to 75 years $($ mean $=66.38 ; \mathrm{SD}=3.9)$.

\section{Measures}

The Beck Depression Inventory Second Edition (BDI-II; Beck, Steer, \& Brown, 1996) is a 21-item self-report measure of symptoms of depression. The internal consistency was assessed by means of Cronbach's alpha (.92). Respondents choose statements that reflect how they have felt over the past 2 weeks. BDI-II scores range between 0 and 63; categorical depression ratings are 'minimal' (013), 'mild' (14-19), 'moderate' (20-28), and 'severe' (29-63). The authors found, in their assessed clinical sample, a cut-off of 17 or greater with a $93 \%$ true-positive rate and an $18 \%$ false-positive rate.

The BHS (Beck \& Steer, 1987; Beck et al., 1974; Pompili et al., 2009) is a 20-item true or false self-report scale developed to operationalize the construct of hopelessness. Beck originally used this scale with adult psychiatric patients in order to predict who would commit suicide and who would not. Responding to the 20 true or false items on the BHS, individuals can either endorse a pessimistic statement or deny an optimistic statement. Research consistently supports a positive relation between BHS scores and measures of depression, suicidal intent, and current SI. Instead of the response format that includes the true/false endorsement, in this case, to increase the response sensitivity, we used a Likert-type scale with 5-point format having two extreme options of 'very strongly disagree' (0) and 'very strongly agree' (4). To obtain the measure of hopelessness, we reversed the scoring of positive items, and then we summed the 20 items to yield a total score ranging from 0 to 80 . In this sample, the instrument showed a good reliability (Cronbach's alpha $=.83$ ). This change is consistent with previous research measuring hopelessness in the elderly (Abraham, 1991; Neufeld, O'Rourke, \& Donnelly, 2010). Several authors have noted that although generally accepted in clinical and research contexts, the original dichotomous response format is likely to constrict measurement variance and determine lower sensitivity (Hayslip, Lopez, \& Nation, 1991; Hill, Gallagher, Thompson, \& Ishida, 1988; Neufeld et al., 2010). In particular, 
Neufeld et al. (2010, p. 752) assessed SI in a sample of older adults, changing the response format of the BHS to a Likert-type scale. The results of the study provided support to the revised response format of the BHS, showing good psychometric properties and enhancing measurement sensitivity of SI among older adults.

The 9 Attachment Profile (9AP; Candilera, 2007) is a semi-projective test for assessing the quality of the interpersonal relationships based on self-other perception and internal working models of adult attachment. Bowlby's notion of attachment representation involves ideas regarding both the self and others, whereas a person's representation of the self and the other could be characterized by one of the two orientations, i.e. positive or negative. This measure consists of seven basic pictures. Each picture represents a situation with one black figure and one or more white figures in different environments. The presentation of each picture is accompanied by two equal lists of nine differential semantic scales anchored by opposed terms. In the first list, participants are asked to rate their self-perception on a 9-point scale for each differential semantic, and in the second list their perception of the others. 9AP provides 18 bipolar scales regarding psychological and emotional constructs, nine self-related and nine other-related: acceptance-rejection, friendliness-hostility, power-submission, security-insecurity, availabilityunavailability, calm-agitation, satisfaction-dissatisfaction, independence-dependence, lack of competition-competition. Higher scores correspond to the first term of each bipolar scale (positive representation), and lower scores to the second term (negative representation). In summary, we used the two general indicators, self-perception (Cronbach's alpha $=.91$ ) and other-perception (Cronbach's alpha $=.89$ ), scored by adding up the score of the nine self-related and the nine other-related scales, respectively.

The Zuckerman-Kuhlman-Aluja Personality Questionnaire (ZKA-PQ; Aluja, Kuhlman, \& Zuckerman, 2010 ) is a 200 -item questionnaire based on the theoretical constructs of the alternative five-factor model of personality. The instrument measures aggressiveness (physical aggression, verbal aggression, anger, hostility), activity (work compulsion, general activity, restlessness, work energy), extraversion (positive emotions, social warmth, exhibitionism, sociability), neuroticism (anxiety, depression, dependency, low self-esteem), and sensation seeking (thrill and adventure seeking, experience seeking, disinhibition, boredom susceptibility/impulsivity). The authors reported that alphas for aggressiveness, activity, extraversion, neuroticism, and sensation seeking were .78-.81, $.76-.73, .75-.75, .74-.79$, and .70-.72 for the Spanish and American samples, respectively.

\section{Statistical analyses}

We used two-tailed $t$-tests for continuous variables, and chi-square tests with Yates' correction where appropriate for categorical variables. Factorial invariance and latent mean structure were tested by structural equation modeling (SEM). SEM relies on several statistical tests to determine the adequacy of model fit to the empirical data. In SEM, it is possible to analyze relations between observed variables and latent variables in addition to a measurement model. The measurement model specifies hypotheses about the relations between a set of observed variables and the unobserved variables or constructs that they were designed to measure. Confirmatory factor analysis (CFA) allows for a test of specific hypotheses concerning the relation between observed variables and their underlying latent constructs. On the basis of existing literature and consistent with theory, we anticipated several relation patterns a priori and then tested the hypotheses statistically. CFA seeks to determine if the number of factors and the loadings of measured (indicator) variables conform to what is expected by the pre-established theory. Our a-priori assumption was that each factor would be associated with a specified subset of indicator variables. The CFA implies the formal specification of the measurement instrument in terms of a factor model, the statistical fitting of the factor model to the observed data (variances and covariances or correlations), the assessment of fit, and the interpretation of the results if the model is consistent with the data (Bollen, 1989; Byrne, 2010).

A series of multigroup CFA-nested models were constructed to examine the evidence of measurement invariance (i.e. configural, metric, scalar, strict) and then the latent mean structures (Vandenberg \& Lance, 2000). In testing for invariance, it is preferable first running a model in which only the factor loadings are constrained equal (i.e. a measurement model), and accordingly, provided with evidence of group equivalence, these factor-loading parameters remain constrained, and equality constraints are then placed on the factor variances and covariances (i.e. structural model) (Byrne, 2010).

Configural invariance requires that each common factor is associated with identical measurement sets across groups, examining the strength of the relation between the observed variables and their underlying latent constructs. This model has no equality constraints imposed on the estimated parameters, thus permitting different parameter values across groups. This multigroup model serves two important functions: it allows for invariance tests to be conducted across the groups simultaneously, and in testing for invariance, the fit of this configural model provides the baseline value against which subsequent specified invariance models can be compared.

Metric invariance is tested by imposing equality constraints on corresponding factor loadings and comparing the fit of the constrained model to the configural model. Metric invariance suggests that the observed variables have identical meanings across groups. Scalar invariance requires that the intercepts of the observed variables are the same across groups and is tested by imposing equality constraints on the intercepts and assessing model fit in comparison to the metric invariant model. Strict invariance assesses whether the data support equality of variables and factor residual variances across groups.

We used the following criteria to evaluate the overall goodness of fit. The $\chi^{2}$ value close to 0 indicates little difference between the expected and observed covariance 
matrices, with the probability level greater than .05 , evidencing the absence of meaningful unexplained variance. Moreover, to estimate a better goodness of fit, due to the fact that $\chi^{2}$ is sensitive to sample size, we calculated the ratio of $\chi^{2}$ to degrees of freedom that should be less than 3 as acceptable data-model fit. In addition to the $\chi^{2} / d f$ test, we utilized the comparative fit index (CFI; Bentler, 1990), the Tucker-Lewis index (TLI; Tucker \& Lewis, 1973), the root mean square error of approximation (RMSEA; Steiger, 1990) and the standardized root mean square residual (SRMR; Jöreskog \& Sörbom, 1996). Indicators of a well-fitting model are evidenced by CFI and TLI greater than .95, RMSEA less than .06, and SRMR less than .08 (Browne \& Cudeck, 1989; Hu \& Bentler, $1998,1999)$. We compared nested models using the $\chi^{2}$ difference test, and the change in CFI. A critical ratio (CR), as $z$ statistic, equal or greater than 1.96 indicates a difference between latent means (Cheung, 2008; Cheung \& Rensvold, 2002).

We conducted multigroup CFA-nested models to examine whether or not the components of the measurement model and the underlying theoretical structure were invariant across the two groups of interest (i.e. the Young Adults and the Older Adults) to test the hypothesis if the loadings of the observed variables on the factors conform to what would be expected on the basis of pre-established theory (Byrne, Shavelson, \& Muthén, 1989). Specifically, we tested for equivalency of the factorial measurement, the scales representing the observed variables, and the underlying latent structure as well as the relations among dimensions of personality and SI risk across the Young Adults and the Older Adults.

To test for factorial equivalence, given that the estimation of baseline models involves no between-group constraints, the data can be analyzed separately for each group. Then we used the nine scales to measure the underlying constructs of personality and suicidal ideation, which provided the basis for the hypothesized model in the determination of the baseline model for each group separately. If this model fits the data well for both the groups, it will remain the hypothesized model under the test for equivalence across the two groups.

We examined the configural invariance to investigate multigroup representation of the baseline models with freely estimated factor loadings for each of the groups simultaneously. This configural model provides the baseline value against which all subsequent specified invariance models were compared. Provided the evidence of invariance between the two groups, we estimated latent mean differences, that is unobserved means derived from the observed variable means loading on the factor. We chose the Young Adults as reference group, and fixed to zero the means of the latent factors, and the Older Adults as comparison group, and let the means of the latent factors vary freely.

All analyses were carried out using SPSS 17.0 (SPSS Inc., Chicago, IL, USA). CFA was applied with the use of AMOS 16.0 (AMOS: analysis of moment structures) and maximum likelihood estimation (Arbuckle, 2007).

\section{Results}

As expected, there was a significant difference between the age of the two groups $\left(t_{(653)}=133.01 ; p<.001\right)$. As regards gender, the Young Adults comprised 179 (52.8\%) (mean = 25.8; SD = 3.7) males and 160 (47.2\%) females (mean $=26.2 ; \mathrm{SD}=3.9)$. No difference was found between the age of the participants in this group $\left(t_{(337)}=\right.$ $.81 ; p=.41)$. The Older Adults comprised $153(48.4 \%)$ $($ mean $=66.1 ; \mathrm{SD}=3.7)$ males and $163(51.6 \%)$ females (mean $=66.6 ; \mathrm{SD}=4.1$ ), and no difference was found between the age of the participants in this group $\left(t_{(314)}=\right.$ $1.04 ; p=.29)$. No gender difference was found in the two groups $\left(\chi_{(1)}^{2}=1.25 ; p=.26\right)$, while significant differences were found in the years of education $\left(\chi_{(2)}^{2}=48.6 ; p \leq\right.$ $.001)$, as among the Older Adults there were more individuals with less years of education (23.7\%), and less individuals with more years of education $(25.9 \%)$. On the basis of the working status, participants were divided into two groups: Unemployed and Employed. No differences were found in the working status between the Young Adults and the Older Adults $\left(\chi_{(1)}^{2}=.05 ; p=.80\right)$. The sociodemographic characteristics are summarized in Table 1.

\section{Baseline models}

When we tested a model with all nine observed variables, namely depression, hopelessness, and neuroticism as indicators of suicidal ideation, and self-other perception, aggressiveness, activity, extraversion, and sensation

Table 1. Sociodemographic characteristics of subjects.

\begin{tabular}{lcccc}
\hline Characteristics & Young Adults $(N=339)$ & Older Adults $(N=316)$ & Statistics & $p$ \\
\hline Age (years) & $26.02 \pm 3.8^{\mathrm{a}}$ & $66.38 \pm 3.9^{\mathrm{a}}$ & $t_{(653)}=133.01$ & $<.001$ \\
Sex & 52.8 & & $\chi_{(1)}^{2}=1.25$ & .26 \\
$\quad$ Males (\%) & 47.2 & 48.4 & & \\
$\quad$ Females (\%) & 5.0 & 51.6 & $\chi_{(2)}^{2}=48.6$ & $<.001$ \\
Education & 58.4 & 23.7 & & \\
$\quad \leq 8(\%)$ & 50.3 & & \\
$\leq 13(\%)$ & 25.9 & $\chi_{(1)}^{2}=.05$ & .80 \\
$\quad>13(\%)$ & 36.6 & & & \\
Working status & & 34.5 & & \\
$\quad$ Employed\% & 35.4 & 65.5 & & \\
$\quad$ Unemployed\% & 64.6 & & & \\
\hline
\end{tabular}

${ }^{\mathrm{a}}$ Values shown as mean $\pm \mathrm{SD}$. 
Table 2. Goodness-of-fit statistics in determination of baseline models.

\begin{tabular}{|c|c|c|c|c|c|c|c|}
\hline Model (Young Adults) & $\chi_{(d f)}^{2}$ & $p$ & $\chi^{2} / d f$ & CFI & TLI & SRMR & RMSEA \\
\hline (1) Hypothesized two-factor model & $48.03_{(8)}$ & $<.001$ & 6.00 & .978 & .959 & .045 & .087 \\
\hline $\begin{array}{l}\text { (2) Model } 1 \text { with one error of covariance specified } \\
\text { (self and other perception) }\end{array}$ & $42.66_{(7)}^{(0)}$ & $<.001$ & 6.09 & .980 & .958 & .042 & .088 \\
\hline $\begin{array}{l}\text { (3) Model } 2 \text { with one error of covariance specified } \\
\text { (depression and hopelessness) }\end{array}$ & $23.84_{(6)}$ & .001 & 3.97 & .990 & .975 & .031 & .067 \\
\hline \multicolumn{8}{|l|}{ Model (Older Adults) } \\
\hline (1) Hypothesized two-factor model & $31.41_{(8)}$ & $<.001$ & 3.92 & .973 & .950 & .050 & .096 \\
\hline $\begin{array}{l}\text { (2) Model } 1 \text { with one error of covariance specified } \\
\text { (self and other perception) }\end{array}$ & $30.23_{(7)}$ & $<.001$ & 4.31 & .973 & .943 & .048 & .103 \\
\hline $\begin{array}{l}\text { (3) Model } 2 \text { with one error of covariance specified } \\
\text { (depression and hopelessness) }\end{array}$ & $19.53_{(6)}$ & .003 & 3.25 & .985 & .961 & .039 & .085 \\
\hline
\end{tabular}

seeking as indicators of personality, the results were unsatisfactory and statistically irrelevant, with all fitted indices outside the accepted values, and the loadings of aggressiveness (.038), activity (.168) and sensation seeking (.017) extremely low. Hence, we excluded these last three variables from the model. The fit to the data of the first model with two latent factors and three variable indicators for each one was poor for both the Young Adults $\left(\chi_{(8)}^{2}=43.03 ; p<.001 ; \mathrm{CFI}=.978 ; \mathrm{RMSEA}=.087\right)$ and the Elderly $\left(\chi_{(8)}^{2}=31.41 ; p<.001 ;\right.$ CFI $=.973$; RMSEA $=.096)$. These results evidenced a misspecification, and the modification indices suggested that model fit would be improved with the estimation of the error covariance between self and other perception. This specification yielded a moderate change in the goodness-of-fit statistics for both the Young Adults $\left(\chi_{(7)}^{2}=42.66 ; p<\right.$ .001 ; CFI $=.980$; RMSEA $=.088)$ and for the Older Adults $\left(\chi_{(7)}^{2}=30.23 ; p<.001 ; \mathrm{CFI}=.973\right.$; RMSEA $=$ $.103)$. The suggested subsequent estimation of the error covariance between depression and hopelessness, improved considerably the goodness-of-fit statistics. These modifications to the initially hypothesized model of personality and suicidal ideation structures, represent a much better fitting model for both the Young Adults $\left(\chi_{(6)}^{2}=23.84 ; p=.001 ; \mathrm{CFI}=.990 ; \mathrm{RMSEA}=.067\right)$ and the Older Adults $\left(\chi_{(6)}^{2}=19.53 ; p=.003\right.$; CFI $=$ .985 ; RMSEA $=.085)$. All goodness-of-fit statistics for the baseline models in each group are summarized in Table 2.

\section{Configural model}

Results of this multigroup model testing for configural invariance revealed a $\chi_{(12)}^{2}=43.38 ; \chi^{2} / d f=3.61$; CFI $=$
.988 ; RMSEA $=.052$, as expected, indicating that the hypothesized multigroup model was well fitting across the Young Adults and the Older Adults (cf. Model 1, Table 3).

\section{Metric invariance}

To test metric invariance, we imposed equality constraints on all factor loadings across both groups (cf. Model 2, Table 3). The fit of this model to the data was acceptable, and modestly better fitting than the configural model $\left(\chi_{(16)}^{2}=53.38 ; \chi^{2} / d f=3.33 ; \mathrm{CFI}=.986 ; \mathrm{RMSEA}=\right.$ $.049)$.

\section{Scalar invariance}

Model 3 in Table 3 represents the scalar invariance tested by constraining item intercepts to be equal across the groups, which resulted in Model 3 being indistinguishable from Model $2\left(\chi_{(19)}^{2}=54.16 ; \chi^{2} / d f=2.85 ; \mathrm{CFI}=.987\right.$; RMSEA = .044).

Strict invariance. Model 4 (Table 4) tested whether variables and factor error variances were equal for both of the groups. The fit of this model was excellent and significantly better than the fit of Models 2 and $3\left(\chi_{(27)}^{2}=\right.$ $61.74 ; \chi^{2} / d f=2.28$; CFI $=.987$; RMSEA $\left.=.036\right)$. These results indicated that the error variances for the two latent factors and the eight observed variables were identical across groups. In all nested models the differences in CFI were $\leq .01$, reflecting model invariance (Cheung, 2008; Cheung \& Rensvold, 2002).

The results indicate that the Elderly latent mean scores do not differ from Young Adults latent mean scores, and

Table 3. Goodness-of-fit statistics for tests of multigroup invariance.

\begin{tabular}{|c|c|c|c|c|c|c|c|c|}
\hline & $\chi_{(d f)}^{2}$ & $\chi^{2} / d f$ & $\Delta \chi^{2}\left(\Delta_{d f}\right)$ & CFI & $\Delta \mathrm{CFI}$ & TLI & SRMR & RMSEA \\
\hline (1) Configural & $43.38_{(12)}$ & 3.61 & & .988 & & .971 & .031 & .052 \\
\hline (2) Equal factor loadings (metric) & $53.38_{(16)}$ & 3.33 & $10.00_{(4)}$ & .986 & .002 & .974 & .034 & .049 \\
\hline (3) Equal indicator intercepts (scalar) & $54.16_{(19)}$ & 2.85 & $.78_{(3)}$ & .987 & .001 & .979 & .034 & .044 \\
\hline (4) Equal indicator error variances (strict) & $61.74_{(27)}$ & 2.28 & $7.58_{(8)}$ & .987 & $<.001$ & .986 & .032 & .036 \\
\hline
\end{tabular}

Note: $\Delta \chi^{2}\left(\Delta_{d f}\right)=$ chi-square (degrees of freedom) difference. $\Delta \mathrm{CFI}=$ difference in CFI, when change is $\leq .01$ reflects model invariance. 
Table 4. Estimates of the two groups.

\begin{tabular}{|c|c|c|c|c|c|}
\hline \multirow[b]{2}{*}{ Latent factors } & \multirow[b]{2}{*}{ Variables indicators } & \multicolumn{2}{|c|}{ Young Adults $(N=339)$} & \multicolumn{2}{|c|}{ Older Adults $(N=316)$} \\
\hline & & $\begin{array}{l}\text { Factor } \\
\text { loadings }\end{array}$ & $\begin{array}{l}\text { Squared multiple } \\
\text { correlations }\end{array}$ & $\begin{array}{l}\text { Factor } \\
\text { loadings }\end{array}$ & $\begin{array}{l}\text { Squared multiple } \\
\text { correlations }\end{array}$ \\
\hline \multicolumn{6}{|c|}{ Suicidal ideation } \\
\hline & Depression (BDI-II) & .747 & .558 & .726 & .527 \\
\hline & Hopelessness (BHS) & .720 & .519 & .586 & .343 \\
\hline & Neuroticism (ZKA_PQ) & .910 & .828 & .899 & .808 \\
\hline \multicolumn{6}{|l|}{ Personality } \\
\hline & Self-perception (9AP) & .730 & .533 & .756 & .572 \\
\hline & Other-perception (9AP) & .734 & .538 & .739 & .546 \\
\hline & Extraversion (ZKA-PQ) & .855 & .731 & .886 & .784 \\
\hline
\end{tabular}

the inspection of the latent mean estimates revealed no significant differences both in suicidal ideation $(.188$; $\mathrm{CR}=$ $.466 ; p=.641)$ and in personality $(-1.074 ; \mathrm{CR}=.466$; $p=.714$ ). Goodness-of-fit results demonstrated that the model with constrained loadings and item intercepts displayed a good fit to the data $\left(\chi^{2}{ }_{(20)}=70.05 ; \chi^{2} / d f=3.50\right.$; $\mathrm{CFI}=.973 ; \mathrm{TLI}=.959 ; \mathrm{SRMR}=.037$; RMSEA $=.062$ ).

The results of the model employed in the comparison between the latent mean structures (the Elderly) are presented in Figure 1. High negative correlations were found between the two latent factors, suicidal ideation and personality, both in the Young Adults $(r=-.59)$ and in the Older Adults $(r=-.50)$. In the two groups, the factor loadings ranged from 0.59 to 0.91 , and the squared multiple correlations, which indicate the amount of variance in the observed variables that is accounted for by the common factors, ranged from $34 \%$ to $89 \%$. All estimates are reported in Table 4.

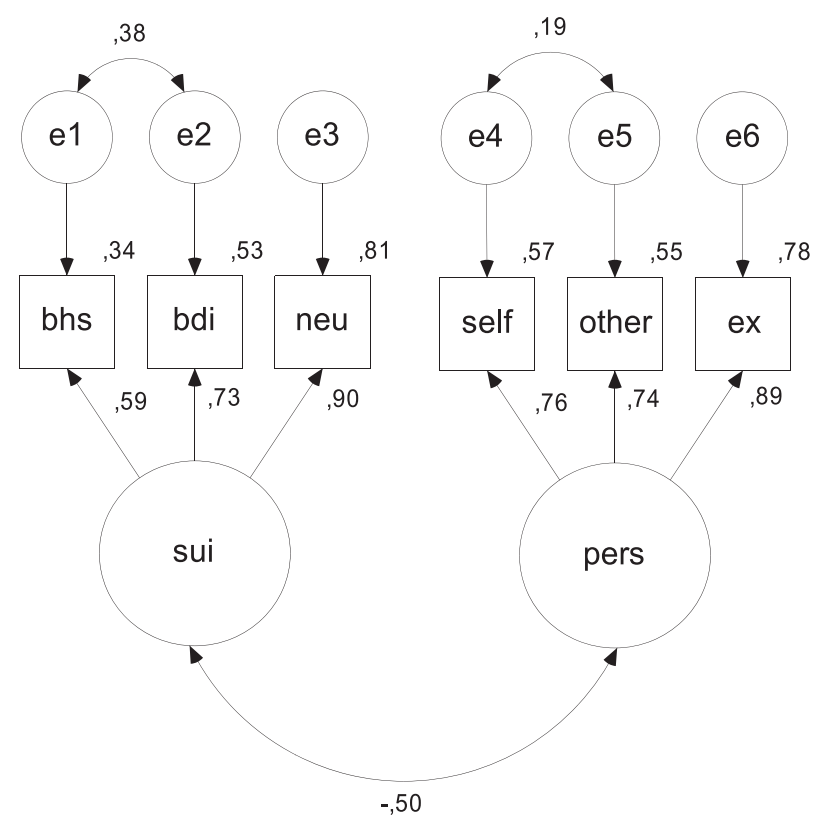

Figure 1. Structural model (Older Adults). Note: sui: suicidal ideation; pers: personality; BHS: hopelessness; BDI: depression; neu: neuroticism; Self: self-perception; Other: other-perception; ex: extraversion.

\section{Discussion}

In the present study, we tested a theoretical model representing a latent structure composed by a pattern of associations among personality characteristics and risk factors for SI across young adults and older adults. We hypothesized that old adults high in neuroticism, introversion, and negative self-other perception would be more likely to present increased risk for SI than younger adults, consistent with the literature indicating the elderly as less likely to cope with specific age-related stressful life events (Kendler, Gardner, \& Prescott, 2003). The hypothesis was not supported by the data analysis. In a series of multigroup CFA-nested models, we found measurement invariance. The results show a comparable pattern of relations between the observed variables and their underlying latent constructs across the two groups, implying that both the young and the older adults scoring high in specific personality (self-other perception and introversion) and psychiatric (depressive symptoms and hopelessness) dimensions were similarly exposed to increased risk of SI.

The distribution of the two observed variables (selfother perception and introversion) indicated a common association underlying the personality latent factor. The three observed variables (neuroticism, depressive symptoms, and hopelessness) underlying the suicidal ideation latent factor were also well estimated, implying the adequacy of the theoretical model fit to the empirical data. In the suicidal ideation factor, neuroticism was related to a perception of negative mood and future expectations, whereas in the personality factor, introversion was associated with a negative perception of the self and the others.

Our findings support evidence that the elderly high in neuroticism and introversion are at increased risk of SI, consistently with previous research reports (Lynch et al., 1999; Tsoh et al., 2005; Useda et al., 2004; Wiktorsson et al., 2013). Moreover, we consider these results even more interesting for two reasons: first, we referred to personality traits as complex and multifaceted psychobiological factors, as implied by the adoption of the alternative five-factor models of personality. Second, we found that attachment dimensions are associated to personality traits in determining risk for SI in the elderly, confirming results from recent studies in different age groups (Davaji et al., 2010; Sheftall et al., 2013). However, research aiming to clarify the associations between such dimensions is needed. 
We found a common underlying latent structure for elderly and young adults, suggesting that most predictors of SI are common across these groups, although it is possible that the salience of their associations may vary across age. Furthermore, research showed that different suicidality rates occur in the elderly from different demographic backgrounds and social conditions (Cattell, 2000), and accordingly, the presence of specific life stressors may mediate the association between personality and SI in this group.

These results outline a theoretical model of invariance between SI and personality variables among a population of the elderly and young adults, indicating a pattern of continuity across age. One notable implication is the importance of considering dysfunctional personality dimensions as significant risk factors for SI in both groups. In particular, in this study we focused on testing the invariance of factors between the two groups, and we believe that future research efforts should be addressed to examining the structure of these factors, especially from a mediational perspective. This will allow to clarify direct and indirect relations among various sets of variables and to outline more comprehensive theoretical models.

In addition, previous studies reported that the elderly who have experienced psychological distress related to specific social conditions - e.g. social isolation, loneliness, and widowhood - are a particularly vulnerable age group (Pompili et al., 2008; Szanto et al., 2001). Consistently, the results of the present study have remarkable practical value for clinicians working with the elderly. First, they indicate the need for specific training in recognizing and assessing SI risk factors in the elderly distressed individuals. Second, trained personnel should support the implementation of information, assessment, and prompt intervention policies in community-based old age psychiatry services as well as in medical and psychological emergencies. Third, effective public policy should be designed and enhanced in order to ensure accessibility of quality mental health care services to the elderly, especially those assessed as neurotic and/or introverted, and with negative self-other perceptions.

The present study has some notable limitations. First, although providing good psychometric properties, it is possible that the self-reported nature of data could have biased results by misleading or spurious correlations, and research integrating multimodal data collection strategies should be implemented. Second, the sample consisted of residents in Italy, and therefore results are not generalizable to other cultural contexts. Further examination of the theoretical model with more comprehensive samples (including residents in other Italian regions where suicidal rates are lower, as well as residents in other countries) may reveal informative. Third, because this study is based on cross-sectional data, a causal interpretation among relations of variables is not allowed, requiring the theoretical model to be tested in longitudinal research. Finally, in this investigation hopelessness was referred to as a proxy of SI risk. In this regard, although research demonstrated the predictive power of the BHS (Pompili et al., 2009; Pompili et al., 2011), it is possible that false positives may be induced by other contributing factors, limiting the validity of results.

Nevertheless, besides these limitations, the associations of variables found in our comprehensive analysis offer researchers and clinicians a robust measurement model. We highlight here the importance of improving research, particularly aiming at identifying risk factors for suicidality in the elderly and providing a more comprehensive theoretical framework. Understanding the structure of these relations will allow for development and implementation of advanced prevention and treatment policies.

\section{Acknowledgements}

This work was completed with the assistance of S\&P Statistics and Psychometrics Ltd, Rome, Italy.

\section{References}

Abraham, I.L. (1991). The Geriatric Depression Scale and hopelessness index: Longitudinal psychometric data on frail nursing home residents. Perceptual and Motor Skills, 72, 875880. doi: $10.2466 /$ pms.1991.72.3.875

Aluja, A., Kuhlman, M., \& Zuckerman, M. (2010). Development of the Zuckerman-Kuhlman-Aluja Personality Questionnaire (ZKA-PQ): A factor/facet version of the ZuckermanKuhlman Personality Questionnaire (ZKPQ). Journal of Personality Assessment, 92, 416-431. doi: 10.1080/ 00223891.2010 .497406

Arbuckle, J.L. (2007). Amos 16 user's guide. Chicago, IL: SPSS.

Baker, S.P., Hu, G., Wilcox, H.C., \& Baker, T.D. (2013). Increase in suicide by hanging/suffocation in the U.S., 2000-2010. American Journal of Preventive Medicine, 44, 146-149. doi: 10.1016/j.amepre.2012.10.010

Beck, A.T., \& Steer, R.A. (1987). Manual for the Beck Depression Inventory. San Antonio, TX: The Psychological Corporation.

Beck, A.T., Steer, R.A., \& Brown, G.K. (1996). Manual for the Beck Depression Inventory-II. San Antonio, TX: The Psychological Corporation.

Beck, A.T., Weissman, A., Lester, D., \& Trexler, L. (1974). The measurement of pessimism: The hopelessness scale. Journal of Consulting and Clinical Psychology, 42, 861-865.

Bentler, P.M. (1990). Comparative fit indexes in structural models. Psychological Bulletin, 107, 238-246. doi: 10.1037/ 0033-2909.107.2.238

Block, J. (1995). A contrarian view of the five-factor approach to personality description. Psychological Bulletin, 117, 187215. doi: 10.1037/0033-2909.117.2.187

Bollen, K.A. (1989). Structural equations with latent variables. New York, NY: Wiley.

Bowlby, J. (1969). Attachment and loss: Vol. 1. Attachment. New York, NY: Basic Books.

Bowlby, J. (1973). Attachment and loss: Vol. 2. Separation. New York, NY: Basic Books.

Bowlby, J. (1980). Attachment and loss: Vol. 3. Loss, sadness and depression. New York, NY: Basic Books.

Browne, M.W., \& Cudeck, R. (1989). Single sample cross-validation indices for covariance structures. Multivariate Behavioral Research, 24, 445-455. doi: 10.1207/s15327906mbr2404_4

Byrne, B.M. (2010). Structural equation modeling with AMOS: Basic concepts, applications, and programming (2nd ed.). New York, NY: Routledge.

Byrne, B.M., Shavelson, R.J., \& Muthén, B. (1989). Testing for the equivalence of factor covariance and mean structures: The issue of partial measurement invariance. Psychological Bulletin, 105, 456-466. doi: 10.1037/0033-2909.105.3.456 
Candilera, G. (2007). 9 Attachment Profile (9AP). Manual and norms. Roma: Scione Editore.

Cattell, H. (2000). Suicide in the elderly. Advances in Psychiatric Treatment, 6, 102-108. doi: 10.1192/apt.6.2.102

Cheung, G.W. (2008). Testing equivalence in the structure, means, and variances of higher order constructs with structural equation modeling. Organizational Research Methods, 11, 593-613. doi: 10.1177/1094428106298973

Cheung, G.W., \& Rensvold, R.B. (2002). Evaluating goodnessof-fit indices for testing measurement invariance. Structural Equation Modelling, 9, 233-255. doi: 10.1207/ S15328007SEM0902_5

Ciulla, L., Lopes Nogueira, E., da Silva Filho, I.G., Levi Tres, G., Engroff, P., Ciulla, V., \& Cataldo Neto, A. (2014). Suicide risk in the elderly: Data from Brazilian public health care program. Journal of Affective Disorders, 152, 513-516. doi:10.1016/j.jad.2013.05.090

Conwell, Y., Duberstein, P.R., Cox, C., Herrmann, J., Forbes, N., \& Caine, E.D. (1998). Age differences in behaviors leading to completed suicide. The American Journal of Geriatric Psychiatry, 6, 122-126. doi: 10.1097/00019442199805000-00005

Costa, P.T., Jr, \& McCrae, R.R. (1992). Revised NEO Personality Inventory (NEO-PI-R) and NEO Five-Factor Inventory (NEO-FFI) professional manual. Odessa, FL: Psychological Assessment Resources.

Davaji, R.B.O., Valizadeh, S., \& Nikamal, M. (2010). The relationship between attachment styles and suicide ideation: The study of Turkmen students, Iran. Procedia - Social and Behavioral Sciences, 5, 1190-1194. doi: 10.1016/j. sbspro.2010.07.259

Fraley, R.C., \& Shaver, P.R. (2000). Adult romantic attachment: Theoretical developments, emerging controversies, and unanswered questions. Review of General Psychology, 4, 132-154. doi: 10.1037//1089-2680.4.2.132

Haaga, D.A.F., Yarmus, M., Hubbard, S., Brody, C., Solomon, A., Kirk, L., \& Chamberlain, J. (2002). Mood dependency of self-rated attachment style. Cognitive Therapy and Research, 26, 57-71. doi: 10.1023/A:1013841720939

Hayslip, B., Jr., Lopez, F.G., \& Nation, P. (1991). Hopelessness in community-residing aged persons: A viable construct? Journal of Personality Assessment, 57, 498-505. doi: 10.1207/s15327752jpa5703_8

Hill, R.D., Gallagher, D., Thompson, L.W., \& Ishida, T. (1988). Hopelessness as a measure of suicidal intent in the depressed elderly. Psychology and Aging, 3, 230-232. doi: 10.1037/ 0882-7974.3.3.230

Hu, L., \& Bentler, P.M. (1998). Fit indices in covariance structure modeling: Sensitivity to underparameterized model misspecification. Psychological Methods, 4, 424-453. doi: 10.1037/1082-989X.3.4.424

Hu, L., \& Bentler, P.M. (1999). Cutoff criteria for fit indexes in covariance structure analysis: Conventional criteria versus new alternatives. Structural Equation Modeling, 6, 1-55. doi: $10.1080 / 10705519909540118$

Istituto Nazionale di Statistica. (2011). I suicidi in Italia [Suicides in Italy]. Retrieved from http://www.istat.it/it/archivio/ 68812

Jöreskog, K.G., \& Sörbom, D.G. (1996). LISREL 8: User's reference guide. Chicago, IL: Scientific Software International.

Juurlink, D.N., Herrmann, N., Szalai, J.P., Kopp, A., \& Redelmeier, D.A. (2004). Medical illness and the risk of suicide in the elderly. Archives of Internal Medicine, 164, 1179-1184. doi: 10.1001/archinte.164.11.1179

Kendler, K.S., Gardner, C.O., \& Prescott, C.A. (2003). Personality and the experience of environmental adversity. Psychological Medicine, 33, 1193-1202.

Legleye, S., Beck, F., Peretti-Watel, P., Chau, N., \& Firdion, J.M. (2010). Suicidal ideation among young French adults: Association with occupation, family, sexual activity, personal background and drug use. Journal of Affective Disorders, 123, 108-115. doi: 10.1016/j.jad.2009.10.016

Lynch, T.R., Johnson, C.S., Mendelson, T., Robins, C.J., Krishnan, K.R.R., \& Blazer, D.G. (1999). Correlates of suicidal ideation among an elderly depressed sample. Journal of Affective Disorders, 56, 9-15. doi: 10.1016/S0165-0327 (99)00022-1

Neufeld, E., O’Rourke, N., \& Donnelly, M. (2010). Enhanced measurement sensitivity of hopeless ideation among older adults at risk of self-harm: Reliability and validity of Likert-type responses to the Beck Hopelessness Scale. Aging \& Mental Health, 14, 752-756. doi: 10.1080/ 13607860903421052

Pompili, M., Iliceto, P., Lester, D., Innamorati, M., Girardi, P., \& Tatarelli, R. (2009). BHS Beck Hopelessness Scale. Firenze: Organizzazioni Speciali.

Pompili, M., Iliceto, P., Luciano, D., Innamorati, M., Serafini, G., Del Casale, A., ... Lester, D. (2011). Higher hopelessness and suicide risk predict lower self-deception among psychiatric patients and non-clinical individuals. Rivista di Psichiatria, 46, 24-30.

Pompili, M., Innamorati, M., Masotti, V., Personnè, F., Lester, D., Di Vittorio, C., ... Amore, M. (2008). Suicide in the elderly: A psychological autopsy study in a North Italy area (19942004). The American Journal of Geriatric Psychiatry, 16, 727-735. doi: 10.1097/JGP.0b013e318170a6e5

Pompili, M., Vichi, M., Masocco, M., Vanacore, N., Innamorati, M., Serafini, G., ... Tatarelli, R. (2010). Il suicidio in Italia. Aspetti epidemiologici e socio demografici [Suicide in Italy. Epidemiological and socio-demograhic aspects]. Quaderni Italiani di Psichiatria, 29, 41-50. doi: 10.1016/j.quip. 2010.05.001

Sheftall, A.H., Mathias, C.W., Furr, R.M., \& Dougherty, D.M. (2013). Adolescent attachment security, family functioning, and suicide attempts. Attachment \& Human Development, 15, 368-383. doi: 10.1080/14616734.2013.782649

Shneidman, E. (1996). The suicidal mind. New York, NY: Oxford University Press.

Steiger, J.H. (1990). Structural model evaluation and modification: An interval estimation approach. Multivariate Behavioral Research, 25, 173-180. doi: 10.1207/s15327906 mbr2502_4

Szanto, K., Prigerson, H.G., \& Reynolds III, C.F. (2001). Suicide in the elderly. Clinical Neuroscience Research, 1, 366-376. doi: 10.1016/S1566-2772(01)00039-1

Tsoh, J., Chiu, H.F.K., Duberstein, P.R., Chan, S.S.M., Chi, I., Yip, P.S.F., \& Conwell, Y. (2005). Attempted suicide in elderly Chinese persons: A multi-group, controlled study. The American Journal of Geriatric Psychiatry, 13, 562-571. doi: 10.1097/00019442-200507000-00004

Tucker, L.R., \& Lewis, C. (1973). A reliability coefficient for maximum likelihood factor analysis. Psychometrika, 38, 1-10. doi: 10.1007/BF02291170

Useda, J.D., Duberstein, P.R., Conner, K.R., \& Conwell, Y. (2004). Personality and attempted suicide in depressed adults 50 years of age and older: A facet level analysis. Comprehensive Psychiatry, 45, 353-361. doi: 10.1016/j. comppsych.2004.06.002

Vandenberg, R.J., \& Lance, C.E. (2000). A review and synthesis of the measurement invariance literature: Suggestions, practices, and recommendations for organizational research. Organizational Research Methods, 3, 4-70. doi: 10.1177/ 109442810031002

Vrshek-Schallhorn, S., Czarlinski, J., Mineka, S., Zinbarg, R.E., \& Craske, M. (2011). Prospective predictors of suicidal ideation during depressive episodes among older adolescents and young adults. Personality and Individual Differences, 50, 1202-1207. doi: 10.1016/j.paid.2011.02.008

Wiktorsson, S., Berg, A.I., Billstedt, E., Duberstein, P.R., Marlow, T., Skoog, I., \& Waern, M. (2013). Neuroticism 
and extroversion in suicide attempters aged 75 and above and a general population comparison group. Aging \& Mental Health, 17, 479-488. doi: 10.1080/13607863. 2012.749835

World Health Organization. (2012). Public health action for the prevention of suicide. Geneva: Author. Retrieved from http://www.who.int/mental_health/publications/prevention_ suicide_2012/en/index.html
Zuckerman, M. (1992). What is a basic factor and which factors are basic? Turtles all the way down. Personality and Individual Differences, 13, 675-681. doi: 10.1016/0191-8869(92) 90238-K

Zuckerman, M., Kuhlman, D.M., Joireman, J., Teta, P., \& Kraft, M. (1993). A comparison of three structural models for personality: The Big Three, the Big Five, and the Alternative Five. Journal of Personality and Social Psychology, 65, 757-768. 